\title{
TRABALHO, EDUCAÇÃO E PRODUÇÃO DO CONHECIMENTO: notas conceituais sobre os fundamentos da(s) Pedagogia(s) Agroecológica(s) ${ }^{1}$
}

Marcio Gomes da Silva²

Resumo: O presente texto tem como objetivo refletir sobre a produção do conhecimento agroecológico e indicar, a partir dessa reflexão, os fundamentos da pedagogia agroecológica. A análise acerca da produção do conhecimento agroecológico será realizada levando em consideração diferentes tempos/espaços de aprendizagens, seja no âmbito dos movimentos sociais, seja no âmbito das escolas do campo. Tentaremos relacionar os interstícios entre a agricultura camponesa e agroecologia, partindo do pressuposto que na agricultura camponesa, o trabalho camponês se configura enquanto um princípio educativo, sob o qual se edificam processos de aprendizagens acerca da produção do conhecimento agroecológico.

Palavras-chave: Trabalho, Educação, Produção do Conhecimento Agroecológico

Resumen: El presente texto tiene como objetivo reflexionar sobre la producción del conocimiento agroecológico e indicar, a partir de esa reflexión, los fundamentos de la pedagogía agroecológica. El análisis acerca de la producción del conocimiento agroecológico se realizará teniendo en cuenta diferentes tiempos / espacios de aprendizajes, sea en el ámbito de los movimientos sociales, sea en el ámbito de las escuelas del campo. Tendremos que relacionar los intersticios entre la agricultura campesina y la agroecología, partiendo del supuesto que en la agricultura campesina, el trabajo campesino se configura como un principio educativo, bajo el cual se edifican procesos de aprendizajes acerca de la producción del conocimiento agroecológico.

Palabras clave: Trabajo, Educación, Producción del Conocimiento Agroecológico

\section{1 - Introdução:}

O presente texto tem como objetivo refletir sobre a produção do conhecimento agroecológico e indicar, a partir dessa reflexão, os fundamentos

\footnotetext{
1 DOI: https://doi.org/10.22409/tn.15i27.p9638

${ }^{2}$ Professor do Departamento de Educação da Universidade Federal de Viçosa - UFV. marcio.gomes@ufv.br

TrabalhoNecessario - www.uff.br/trabalhonecessario; Ano 15, № 27/2017
} 
da pedagogia agroecológica. A análise acerca da produção do conhecimento agroecológico será realizada levando em consideração diferentes tempos/espaços de aprendizagens, seja no âmbito dos movimentos sociais, seja no âmbito das escolas do campo.

Buscando fazer uma aproximação do tema "produção do conhecimento agroecológico" com o campo Trabalho e Educação, a espinha dorsal da análise será realizada por meio da categoria trabalho, no qual tentaremos relacionar os interstícios entre a agricultura camponesa ${ }^{2}$ e agroecologia, partindo do pressuposto que na agricultura camponesa, o trabalho camponês ${ }^{3}$ se configura enquanto um princípio educativo, sob o qual se edificam processos de aprendizagens acerca da produção do conhecimento agroecológico.

A categoria trabalho é polissêmica (FRIGOTTO, 2005), podendo indicar diferentes significados na sociedade capitalista, sendo o mais difundido a ideia de emprego. No entanto, lançaremos mão da categoria trabalho em uma perspectiva ontológica e histórica em que o trabalho é elemento fundante da formação humana, ou seja, do ser social. É a partir do trabalho que nos diferenciamos dos animais, pelo fato de projetarmos a ação, de forma consciente, na relação ser humano natureza, transformando-a por meio do trabalho e garantindo, assim, a nossa própria existência. Sendo assim, o trabalho além de garantir a reprodução biológica do homem também responde "(....) as necessidades de sua vida cultural, social, estética, simbólica, lúdica e afetiva." (FRIGOTTO, 2005,p 2)

Essa perspectiva teórica se ancora em Marx, no qual o trabalho:

(.... ) é um processo de que participam o homem e a natureza, processo em que o ser humano, com sua própria ação, impulsiona, regula e controla seu intercambio material com a

\footnotetext{
${ }^{2}$ Agricultura camponesa "(. ) e o modo de fazer agricultura e de viver das famílias que, tendo acesso à terra e aos recursos naturais que ela suporta, resolvem seus problemas reprodutivos por meio da produção rural, desenvolvida de tal maneira que não se diferencia o universo dos que decidem sobre a alocação do trabalho dos que se apropriam do resultado dessa alocação". (CARVALHO \& COSTA, 2012, p, 26.) in: CALDART, et al 2012. Dicionário da Educação do Campo.

${ }^{3}$ Por trabalho camponês estamos nos referindo a uma manifestação do trabalho na agricultura camponesa, que não se encontra alienado, mas com uma relação intima com o modo de vida que se estabelece a partir desse estilo de agricultura.
}

TrabalhoNecessario - www.uff.br/trabalhonecessario; Ano 15, № 27/2017 
natureza. Defronta-se com a natureza como uma de suas forças. Põe em movimento as forças naturais de seu corpo braços e pernas, cabeça e mãos -, a fim de apropriar-se dos recursos da natureza, imprimindo-lhes forma útil à vida humana. Atuando assim sobre a natureza externa e modificando-a, ao mesmo tempo modifica sua própria natureza (Marx, 2013, p 211).

A perspectiva ontológica ou ontocriativa, portanto, traz a concepção de trabalho enquanto um processo pelo qual nos tornamos humanos, em que 0 trabalho é responsável pela nossa formação enquanto ser humano. $\mathrm{Na}$ perspectiva ontológica, o trabalho é um princípio educativo e deriva "(.....) do fato de que todos os seres humanos são seres da natureza e, portanto, têm necessidades de alimentar-se, proteger-se das interpéries e criar seus meios de vida." (FRIGOTTO, 2005, P 3)

A perspectiva ontológica, portanto, nos traz a dimensão da produção do conhecimento vinculada diretamente a produção e reprodução da existência humana, na qual os processos de aprendizagens se vinculavam diretamente as experiências engendradas no domínio da natureza pelo ser humano, ou seja, “(....) a essência do homem é o trabalho (SAVIANI, 2007, p 154), e este se desenvolve e se modifica ao longo do tempo, por isso um processo histórico e, ao mesmo tempo, um processo educativo. Esses são os fundamentos ontológicos e históricos da relação trabalho educação, históricos por ser produzido ao longo do tempo pela ação humana e ontológicos porque o que é gerado por essa ação humana é o que compõe o ser humano, que o forma enquanto ser social (SAVIANI, 2007).

E na sociedade capitalista, é possível falar em principio educativo do Trabalho? E ao referirmos em agricultura camponesa e agroecologia, que características são atribuídas ao trabalho desenvolvimento no campo e qual conhecimento é produzido a partir dele? Existem saberes produzidos a partir do trabalho camponês? Esses saberes, uma vez reconhecidos, dão suporte a uma pedagogia agroecológica?

O trabalho camponês carrega características específicas em relação a apropriação da terra, que traz traços e relações sociais que mantem atividades 
como mutirão, manejo compartilhado de bens comuns, trabalho associado, que estabelecem processos formativos específicos na relação ser humano natureza. Pleog (2008), ao descrever as características da condição camponesa, nos traz traços dessa identidade entre Trabalho Educação. Apesar da agricultura camponesa também estar inserida na divisão internacional do trabalho, ainda existem e resistem modos de produção na agricultura camponesa que tem no trabalho camponês a mediação dos processos de ensino aprendizagem. Se desenvolve o trabalho assalariado no campo à medida que o capitalismo avança, mas ainda existe o trabalho que possui uma relação intima com os ciclos da natureza, com o conhecimento tradicional ancorado na cultura, no modo como as pessoas do campo vivem e reproduzem a sua existência. Esse tipo de trabalho, que chamamos aqui de trabalho camponês, imprimi uma forma de produção de conhecimento que se aproxima da perspectiva ontológica - na qual o trabalho é a essência da formação humana.

\section{A modernização da agricultura e o conhecimento apropriado pelo capital}

A modernização da agricultura no Brasil provocou mudanças envolvendo diferentes aspectos como relações de trabalho no campo; padrão tecnológico de produção agrícola; distribuição espacial da produção; formação dos complexos agroindustriais e inserção da agricultura no mercado internacional (ALENTEJANO, 2012).

Esse processo está diretamente relacionado com a industrialização do país, na qual a agricultura passa a desempenhar um papel estratégico de abastecimento de alimentos para os recém constituídos centros urbanos, ao mesmo tempo em que se consolida como transferência de mão de obra da zona rural para a zona urbana, no sentido de abastecer as indústrias; ou seja, a agricultura vista como subsidiária ao setor industrial (ALMEIDA, 1997). 
Esse fenômeno ocorreu com intensidade na década de 1960, não só no Brasil, mas em toda América Latina por meio da implantação da chamada Revolução Verde, que se baseia o aumento da produtividade agrícola por meio do uso intensivo de insumos químicos, de variedades de sementes de alto rendimento modificadas geneticamente e por meio da irrigação e da mecanização (ALMEIDA, 1997). O processo de modernização da agricultura foi caracterizado por um padrão tecnológico baseado no binômio químico mineralmecanização; crédito rural privilegiando grandes proprietários; consolidação de cadeias agroindustriais vinculadas à montante com a indústria químicofarmacêutica e de bens de capital; aumento da exportação.

Sua implementação se deu com a intervenção direta do Estado, na qual a atuação ocorreu no sentido de internacionalização da produção de maquinas e insumos para o setor agrícola, a criação de um sistema de pesquisa e extensão da difusão de técnicas de produção vinculadas diretamente ao setor industrial e as condições para o financiamento dos 'pacotes tecnológicos' (ALENTEJANO, 2012).

As consequências desse processo para a agricultura camponesa foram diversas. No âmbito das relações de trabalho houve um avanço do trabalho assalariado, em suas mais diversas manifestações, tais como trabalho temporário, sazonal, enfim, consequências da penetração do capitalismo nas relações produtivas no campo, submetendo a produção e o trabalho ao capital, - que resultou em uma subordinação da agricultura aos "Impérios Agroalimentares" (PLOEG, 2008).

Numa perspectiva histórica, o modelo de agricultura preconizado e difundido pela modernização da agricultura capitalista é muito recente. A apropriação e o domínio dos ecossistemas (e da agricultura) pelo ser humano podem ser datados. Ao se referir a agricultura, essa apropriação nos remete a 10 mil anos, data do registro do surgimento da agricultura na qual o ser humano desenvolveu a habilidade, ou melhor, o conhecimento que lhe permitiu aprender o domínio da domesticação dos animais e o cultivo das espécies de plantas utilizadas para alimentação. Nessa perspectiva de agricultura, a base produtiva se dava por meio de pequena escala, com um alto nível de TrabalhoNecessario - www.uff.br/trabalhonecessario; Ano 15, № 27/2017 
diversidade (biodiversidade) e produtividade ecológica. Nesse contexto, o trabalho é marcado por técnicas de manejo das paisagens que garantiam a reprodução da própria unidade produtiva. Para garantia da subsistência a partir do trabalho eram mobilizados um repertório de conhecimento ecológico localizado, coletivo e holístico acerca dos processos de produção, que se configuravam por estratégias de uso múltiplos dos recursos naturais e a aprendizagem se dava por meio do modo como se dava a organização da sociedade, ou seja, por meio do trabalho, coletivo, compartilhado juntamente com os meios de produção (TOLEDO \& BARRERA BASSOLS, 2015).

Esse modo de apropriação do ecossistema, tradicional ou camponês foi modificado radicalmente a cerca de 200 anos, como expressão e resultado da revolução industrial e cientifica. Essa mudança para um modo agroindustrial não significou apenas o aumento da produção de excedente, mas diversos impactos sociais, econômicos, culturais e ecológicos. Tais impactos referem-se à expulsão de milhares de populações tradicionais, a concentração da posse da terra, a desigualdade econômica e a destruição das culturas e, com elas, todo um repertório de conhecimento utilizado na apropriação dos ecossistemas. De acordo com Toledo \& Barrera Bassols (2015):

Tal mudança obedeceu a lógica de expansão do capitalismo em escala mundial, que exigia a integração das áreas rurais a economia de mercado, a substituição do trabalho pelo capital e o aumento da produtividade, visando abastecer não só uma crescente população urbana, mas também uma nova indústria em plena fase de ascensão. (TOLEDO \& BARRERA BASSOLS,2015, p. 89)

Portanto, à medida que o capitalismo se efetiva e 'integra' a agricultura no processo de reprodução do capital, tanto as relações sociais de produção se modificam, quanto à estrutura do conhecimento mobilizado para manejo dos ecossistemas também se modifica. Esse conhecimento, ancorado nos saberes tradicionais, na cultura e na forma como se organizava o trabalho no manejo das paisagens se institucionaliza e se vincula diretamente a expansão do capitalismo no campo. De acordo com Toledo \& Barrera Bassols (2015) 
(....) as formas como os seres humanos têm conseguido se apropriar com sucesso dos recursos da natureza ao longo do tempo estão sujeitas a uma enorme pressão, exercida por diversos fatores e forças (....) trata-se de um conflito nodal entre as formas agroindustriais e as formas tradicionais de produção (TOLEDO \& BARRERA BASSOLS, 2015, p. 34).

No caso do Brasil, essa institucionalização do conhecimento acerca da agricultura, que passa a ser tido como único conhecimento válido, está intimamente ligada ao surgimento das ciências agrárias, na década de 1920. Coelho (2014), ao descrever o surgimento das ciências agrarias apresenta duas etapas dessa institucionalização. A primeira definida como ciência experiência "(...) aproxima-se da vida cotidiana de quem trabalha no campo, da forma comum da produção agrícola ou pecuária" (COELHO, 2014, p.40). A etapa da ciência experiência, ainda se apropria, ou leva em consideração, um tipo de saber do camponês na estruturação dos seus resultados, que em certa medida ainda são compartilhados. A segunda, instituída a partir da década de 1950, período em que se intensifica a industrialização e a modernização da agricultura capitalista, é denominada de ciência experimento. Essa forma de se fazer pesquisa "(...) gera uma ciência que se faz em um ambiente artificialmente construído para controle de resultados (....) e viabiliza a transformação desse conhecimento em mercadoria" (COELHO, 2014, p.54). Portanto, tem-se por meio da institucionalização da produção de conhecimento a apropriação do capital não apenas dos meios de produção, mas da tecnologia gerada por esse modelo de agricultura.

Silveira (2011) ao analisar a subordinação das política educacionais aos desígnios da políticas de ciência, tecnologia e inovação, evidenciando que esta é parte integrante da dinâmica de internacionalização da economia/tecnologia, revela que, as transnacionais exercem papel fundamental, tanto na expansão das unidades produtivas, provocando concentração, centralização de capital e tecnologia, e estimulando a transferência de tecnologia, quanto na crescente intervenção do Estado para regular o intercâmbio, a circulação e o próprio processo de produção, bem como financiar e estruturar o arcabouço político- 
jurídico dos processos de competição, centralização do capital e reorganização da base produtiva (p. 137).

Nesta perspectiva, continua Silveira (2011), a manifestação do fenômeno de internacionalização da tecnologia, em determinada região ou localidade, varia em função do mercado local, dos concorrentes e fornecedores, de vantagens fiscais oferecidas pelo governo local, da infraestrutura técnico-científica oferecida por universidades, institutos de pesquisa, escolas técnicas e agrotécnicas e, ainda, da disponibilidade de mão-de-obra qualificada em todos os níveis de ensino.

Nesse sentido, se estabelece uma relação entre instituições de pesquisa, vinculadas diretamente a empresas produtoras de conhecimento e ao capital financeiro (por meio de créditos e financiamentos para implantação desse conhecimento na forma de pacotes tecnológicos). O conhecimento tradicional, acumulado por mais de $10 \mathrm{mil}$ anos desde o surgimento da agricultura passa a ser tido como inválido, por não promover como resultado a produção de mercadoria. Ao mesmo tempo, cria-se uma estrutura de produção do conhecimento que possui outras bases, agora vinculada diretamente às empresas produtoras desse conhecimento que a produzem na lógica do capital. As bases anteriores passam a ser negadas. Ao que se refere à construção do conhecimento tradicional, ou o saber do camponês, Iturra, (1993) apud Toledo \& Barrera Bassols (2015) afirma que:

(...) o saber do camponês é obtido através da relação heterogênea entre grupo doméstico e grupo de trabalho, seja em uma comunidade ou em instâncias superiores. 0 conhecimento sobre o sistema de trabalho, a epistemologia, é resultado dessa interação em que a lógica indutiva é aprendida na medida em que se vê fazer e se escuta, para depois poder dizer, explicar e devolver o conhecimento ao longo das relações de parentesco e vizinhança (TOLEDO \& BARRERA BASSOLS, 2015, p. 93)

Ou seja, a expansão capitalista para o campo ao mesmo tempo que gera a apropriação do conhecimento pelo capital, na sua institucionalização e vínculo direto da produção de mercadorias, na forma de tecnologias e técnicas 
de manejo, também gera modificações na estrutura do trabalho, que passa a ser assalariado, alienado e não se configura enquanto um processo de formação humana, mas como um mero processo de reprodução do capital. Entretanto, apesar desse processo hegemônico de produção do conhecimento, existem tempos/espaços em que "(....) as relações entre seres humanos e a natureza podem ganhar contornos diversos" (TIRIBA \& SICHI, 2012, p 10). Sobre esses 'contornos' que trata a próxima seção.

\section{3 - Trabalho e Agroecologia: os diferentes espaços/tempos de produção do conhecimento}

Apesar da modernização da agricultura ter estabelecido um modelo de agricultura hegemônico em relação à agricultura camponesa, vinculado diretamente ao mercado capitalista, especializada, produtora de monocultura, mecanizada e estruturada em latifúndio, em que o trabalho passa a ser assalariado, ainda permanecem formas de agricultura baseadas em racionalidades que se utilizam de conhecimentos tradicionais, definida por Ploeg (2008), como agricultura camponesa. Esse tipo de agricultura, na visão do autor, está fundado principalmente em: a) uma base de recursos limitada, o que leva ao estabelecimento de diferentes estratégias por parte dos camponeses para se chegar a melhores resultados a partir dos recursos disponíveis; b) o trabalho é a centralidade em detrimento aos objetos do trabalho; c) os recursos e materiais são de posse dos que estão diretamente relacionados aos processos de trabalho; d) a produção é relativamente autônoma, pois permite não apenas a produção de mercadorias, mas a própria manutenção da unidade produtiva (PLOEG, 2008).

Por possuir essas características, principalmente em relação ao trabalho, o conhecimento produzido na agricultura camponesa permite estabelecer um vínculo entre Trabalho e Educação, no qual por meio da apropriação dos ecossistemas se produz um conhecimento onde se estabelece as bases científicas e empíricas para produção da agroecologia. 
Adotamos o conceito de agroecologia como ciência, prática e movimento (Wezell et al., 2009). Como ciência, a agroecologia se caracteriza por ser multidisciplinar, aportando as bases do novo paradigma científico, que procura ser integrador, sistêmico. É a partir do diálogo entre cientistas e camponeses, na diversidade de conhecimentos e de técnicas desenvolvidas na agricultura camponesa que se desenvolveu a abordagem da agroecologia enquanto ciência (CALDART, 2016). Como prática, a agroecologia resgata e ressignifica práticas tradicionais de manejo dos agrossistemas com uso de recursos locais (recursos biológicos, naturais e também conhecimentos) que promovem autonomia (PLOEG, 2008). Como movimento, a agroecologia se vincula a luta pela construção da agricultura camponesa no século XXI na qual abarca a socialização da propriedade da terra (e a reforma agrária popular), a diversidade cultural dos povos do campo, e as diferentes formas de trabalho camponês (CALDART, 2016).

A partir dessa definição é possível identificar elementos relacionados diretamente à produção do conhecimento na agroecologia. Um primeiro aspecto se refere ao conhecimento tradicional. Não se trata de "transpor" conhecimentos tradicionais aos contextos atuais da agricultura, mas estabelecer uma reconexão com as formas tradicionais de se fazer agricultura, especificamente da agricultura camponesa, a partir do tipo de trabalho estabelecido na relação com os recursos locais, de forma que tanto o trabalho quanto o conhecimento sejam compartilhados. Isso implica em dois processos distintos: o primeiro refere-se ao compartilhamento comunitário, de práticas e técnicas de manejo ancoradas em saberes ecológicos fundados no modo de vida camponês.

O segundo refere-se às mediações estabelecidas por instituições de pesquisa e agências de Assistência Técnica e Extensão Rural (ATER) que devem incorporar métodos participativos de construção do conhecimento, voltados para conhecimentos locais e, ao mesmo tempo, sistematizados em conhecimentos científicos.

O primeiro aspecto pode ser relacionado com o que Tiriba \& SCHI (2011) denominam de cultura do trabalho, em que: 
(.....) requer um entendimento das relações de produção em que se dão as diversas atividades de reprodução da vida social; e pressupõe a identificação dos elementos materiais (instrumentos, métodos, técnicas, etc) e simbólicos (atitudes, ideias, crenças, hábitos, representações, costumes) partilhados pelos grupos humanos - considerados em suas especificidades de classe, gênero, etnia, religiosidade e geração (TIRIBA \& SICHI, 2011, p 8).

Partir do conhecimento local, significa levar em consideração ou, ter como mediação do processo de ensino aprendizagem (produção do conhecimento) a realidade vivida dos camponeses, ou seja, o trabalho camponês, a forma como o campesinato se reproduz social e economicamente. A produção de sentidos e significados que se dão a partir do trabalho camponês conforma a cultura do trabalho.

Analisando o processo histórico de constituição do "movimento agroecológico"4 no Brasil, Petersen \& Almeida (2006), indicam como gênese do movimento os processos educativos estabelecidos pelas Comunidades Eclesiais de Base $(\mathrm{CEBs})^{5}$, e pela Comissão Pastoral da Terra (CPT). De acordo com os autores, esses processos favoreceram discussões continuas nas comunidades sobre as dificuldades impostas pelas dinâmicas de transformações do campo. Na palavra dos autores:

\footnotetext{
${ }^{4}$ A expressão "movimento agroecológico" tem sido utilizada com certa cautela tanto pelos pesquisadores que escrevem sobre o tema, como pelos ativistas engajados na defesa de uma agricultura de base ecológica. O caráter altamente descentralizado deste movimento, associado, ao que tudo indica, a uma percepção política de que a luta em defesa da agroecologia não deve substituir os movimentos sociais "tradicionais" (o sindicalismo de trabalhadores rurais, os movimentos de luta pela terra, os movimentos e organizações de mulheres), parecem contribuir para que atores e autores evitem, em muitas situações, esta designação. Compreende-se, no entanto, que do ponto de vista conceitual, as lutas em defesa de uma agricultura de base ecológica poderiam ser pensadas, pelo menos em certo sentido, como um movimento social, ou seja, como uma forma de ação coletiva, marcada por uma identidade compartilhada, oponentes claramente identificados e que mobiliza um conjunto extenso de redes informais. Percebe-se, ao mesmo tempo, que a Agroecologia mobiliza também uma série de dimensões que transcendem a esfera do político, relacionadas, ao que se poderia identificar, genericamente, como "práticas de vida alternativas".

${ }^{5}$ Essas experiências estão diretamente relacionadas às resoluções do Concílio Vaticano II, realizado em 1965, no qual a Igreja Católica assumiu uma posição de "opção pelos pobres". Essa concepção de ação religiosa ficou conhecida como Teologia da Libertação, tornando-se responsável pelo engajamento dos agentes eclesiais e se propagando no campo (FAVARETO, 2006).
}

TrabalhoNecessario - www.uff.br/trabalhonecessario; Ano 15, №27/2017 
Esse exercício de vivencia e reflexão comunitária se dá fundamentado em um método dialético que prima por vincular as práticas concretas da vida cotidiana com a leitura crítica do evangelho. Por intermédio do método "ver, julgar e agir", supera-se a dualidade fé-vida fundada na doutrina que reduz 0 'ser cristao' ao domínio intelectual-moral das verdades reveladas e explicitadas pelo magistério eclesiástico (PETERSEN \& ALMEIDA, 2006. P 13).

A dimensão simbólica (religiosidade) e cultural envolvida nas CEBs, ao nosso ver, tem um fundamento na cultura do trabalho. A associação das práticas cotidianas dos camponeses, a reflexão sobre a realidade ancoradas nos aspectos religiosos promoveu um processo de organização política frente as questões concretas que permeavam o campo na década de 1970, período de intensificação dos conflitos no campo. Ou seja, a forma de organização das CEBs gerou um processo de sociabilidade nas comunidades, promovendo ambientes favoráveis ao envolvimento dos camponeses na solução de questões imediatas (PETERSEN \& ALMEIDA, 2006).

Já em relação ao segundo aspecto, qual seja o das mediações estabelecidas por instituições de pesquisa e agências de Assistência Técnica e Extensão Rural (ATER), houve um enfoque metodológico voltado para processos sociais locais, sob as quais se difundiram técnicas e métodos apropriados às situações especificas de inserção das famílias. Silva \& Santos (2016), destacam que por meio de atuação de ONGs ambientalistas vinculadas a REDE PTA ${ }^{6}$, na década de 1980 e 1990, forjaram-se metodologias participativas que buscavam a construção e sistematização do conhecimento, baseados nas dinâmicas, experiências e culturas locais (SILVA \& SANTOS, 2016).

Podemos destacar diferentes instrumentos/técnicas engendradas no Brasil, no âmbito dos movimentos sociais. Tais instrumentos referem-se a

\footnotetext{
${ }^{6}$ O Projeto Tecnologias Alternativas (PTA) surgiu, originalmente, no início dos anos 1980, como um projeto ligado à Federação de Órgãos para Assistência Social e Educacional, organização não governamental fundada em 1961. Esta iniciativa tinha como objetivo pesquisar tecnologias alternativas e disponibilizá-las para os "pequenos produtores". A partir de 1983, como resultado dos debates dos debates ocorridos no chamado "Encontro de Campinas", do qual participaram organizações não governamentais de apoio e assessoria, representantes do movimento sindical, de órgãos públicos e entidades profissionais, o Projeto PTA passará a investir esforços na construção de uma rede de articulação tendo como foco o tema das tecnologias alternativas, processo este que irá se desdobrar na estruturação da Rede Tecnologias Alternativas (Rede TA)
} 
diagnósticos participativos ${ }^{7}$, utilizados na década de 1970 e 1980 na promoção da agroecologia; o "campesino a campesino", que promoveu a partir da interação entre os saberes produzidos pelas experiências de manejo dos camponeses processos de transição agroecológica, especialmente em Cuba; e recentemente as caravanas agroecológicas ${ }^{9}$, que traz o enfoque territorial, principalmente a partir dos conflitos e de relações de poder que se estabelecem em diferentes territórios nos quais se encontram experiências diversas de agroecologia.

São diversas as técnicas e metodologias participativas desenvolvidas na produção desse conhecimento. Entretanto, o que nos interessa aqui é que, independente da técnica utilizada, é o seu fundamento, ou seja, a abordagem teórica que permite uma análise consistente da realidade. Nesse sentido, as metodologias estruturadas de intervenção social se ancoram em saberes produzidos a partir da experiência, ou como definido por (TIRIBA \& SICHI, 2011), nos saberes do trabalho. Ao se referir aos saberes do trabalho associado, Fischer \& Tiriba (2009), denominam que “(.....) são saberes produzidos pelos trabalhadores nos processos de trabalho que se caracterizam pela apropriação coletiva e democrática das decisões quanto a utilização dos excedentes e aos rumos da produção (FISCHER \& TIRIBA, 2009, p 293).

Sendo assim, tem-se um vínculo estreito entre os processos locais de organização dos camponeses e do trabalho associado em termos de mutirão, manejo compartilhado dos recursos naturais, espaços de troca de conhecimentos promovidos e ancorados nas problemáticas locais. Ao mesmo tempo, tem-se também um tipo de trabalho associado vinculado a organizações cooperativas, na organização para o acesso a políticas públicas,

\footnotetext{
${ }^{7}$ Os diagnósticos participativos podem ser definidos como um conjunto de métodos e técnicas que permite a população o reconhecimento da realidade bem como o planejamento das ações que irão incidir sobre a realidade.

${ }^{8}$ Método muito difundido na América Latina, o Campesino a Campesino baseia-se na interação entre agricultores e agricultoras na solução de problemáticas relacionadas ao mano dos agroecossistemas (MACHIN SOSA, et al. 2012).

${ }^{9}$ As caravanas agroecológicas foi uma técnica utilizada na preparação do III Encontro Nacional de Agroecologia, em 2014. A técnica traz a abordagem territorial como enfoque das experiências nos territórios, destacando questões como posse da terra; soberania alimentar, conflitos sócio ambientais, etc. a estrutura metodológica envolve elaboração e roteiro de observação, a partir de temas geradores visitas as experiências agroecológicas e avaliação coletiva das práticas e realidades visitadas. É um exercício descentralizado de analise coletiva dos territórios visando contrastar esses padrões opostos de desenvolvimento rural.
}

TrabalhoNecessario - www.uff.br/trabalhonecessario; Ano 15, № 27/2017 
na construção social de mercados, na formação de lideranças, etc. (SILVA et al., 2014).

Essas iniciativas produzem saberes que são fundamentais para estruturação de processos formativos na agroecologia. Tiriba (2007) analisa que a produção associada produz uma determinada pedagogia. Nesse sentido, a partir dos "saberes do trabalho associado" é possível analisar a relação entre a produção de conhecimento no âmbito da experiência do trabalho associado como matriz formadora da agroecologia, estruturada e voltada para formação de camponeses.

É possível sintetizar a produção do conhecimento na agroecologia a partir dos seguintes aspectos: a) organização das ações a partir das questões colocadas pelos cotidianos das famílias; b) valorização das iniciativas locais das famílias e às formas de proximidade e trabalho coletivo visando otimizar o uso dos recursos locais voltados para busca de autonomia; c) o desenvolvimento de ações de forma a valorizar as relações pré-existentes nas comunidades (PETERSEN \& ALMEIDA, 2006). Essa produção de conhecimento, portanto, tem como eixo central o trabalho, as experiências e saberes produtivos a partir do trabalho camponês em um campo que está em disputa.

\section{1 - Escola do trabalho: fundamento das escolas do campo na produção do conhecimento agroecológico?}

Trazer para a discussão a escola do trabalho e a sua relação com as escolas do campo ${ }^{10}$ é fazer a relação entre o trabalho socialmente necessário como princípio básico da formação, em que o vínculo entre agricultura camponesa e agroecologia se coloca enquanto eixo central para a organização dos conteúdos escolares. De acordo com Caldart (2016), “(...) é preciso encontrar/construir com urgência e paciência caminhos firmes para um vínculo orgânico das escolas do campo com processos de trabalho e de luta que estão

\footnotetext{
${ }^{10}$ A concepção de escola do campo nasce das contradições da luta social e das práticas de educação dos trabalhadores do campo, em que o acesso ao conhecimento e a garantia de escolarização dos sujeitos do campo são parte dessa luta (MOLINA, M.C.; SÁ, L.M., 2012).

TrabalhoNecessario - www.uff.br/trabalhonecessario; Ano 15, № 27/2017
} 
construindo a agricultura camponesa agroecológica com parte da alternativa do trabalho à ordem do capital" (CALDART, 2016, P 2).

Nesse sentido, compreendemos que um dos fundamentos da pedagogia agroecológica são os fundamentos da escola do trabalho. Reconhecemos também que a escola não é o único espaço no qual o conhecimento agroecológico é produzido, no entanto, como nos alerta Saviani (2013) "(....) a escola existe, pois, para propiciar a aquisição dos instrumentos que possibilitam o acesso ao saber elaborado (ciência), bem como o próprio acesso aos rudimentos desse saber." (SAVIANI, 2013, p, 14). Sendo assim, a escola do campo é um dos espaços de formação, na qual as bases científicas dos processos de manejo dos agroecossistemas, bem como de processos organizativos dos camponeses em processo de transição agroecológica, podem ser ensinados, com vínculo direto com a realidade agrária na qual estão inseridos.

Corroborando com a abordagem que $\mathrm{o}$ trabalhador tem $\mathrm{o}$ direito ao saber elaborado historicamente pela humanidade, bem como os seus fundamentos científicos de forma a gerar autonomia e superação das desigualdades, faz-se necessário uma relação estreita entre a escola do campo e a escola do trabalho e a relação da produção do conhecimento agroecológico a partir dessa aproximação.

A escola do trabalho tem dois grandes fundamentos, o primeiro se refere na relação da escola com a realidade, definida por Pistrak (2009) como atualidade. De acordo com Pistrak (2009) "A atualidade é tudo aquilo que na vida da sociedade do nosso período tem requisitos para crescer e desenvolverse, que reúne ao redor da revolução social que está vencendo e irá servir para a construção da nova vida." (PISTRAK, 2009, p 113.). Por meio da atualidade a escola penetra na realidade, tendo no trabalho socialmente necessário o princípio educativo e formativo, sob o qual se edificam métodos de estudos e as questões de formação, como forma de organização dos conteúdos, ou as bases científicas necessárias para formação de seres humanos autônomos, em que a escola assume como objetivo "(.....) não apenas conhecer a atualidade, mas dominá-la" (PISTRAK, 2009, p, 115).

TrabalhoNecessario - www.uff.br/trabalhonecessario; Ano 15, № 27/2017 
O segundo fundamento trata da auto-organização dos estudantes. Para Pistrak (2009), auto-organização trata da participação ativa da criança na organização da escola, como um processo educativo, capaz de formar dirigentes com habilidades de, coletivamente, ter o domino da vida social e da produção. Por meio dos dois grandes pressupostos, qual seja a atualidade e a auto-organização dos estudantes, espera-se que a formação estabelecida seja capaz de desenvolver habilidades como a capacidade de trabalhar coletivamente, capacidade para criatividade organizativa e realização de tarefas de forma organizada (PISTRAK, 2009).

A essência desse processo formativo é o trabalho como mediação do processo de ensino aprendizagem, de acordo com Pistrak (2009, p 206):

O trabalho será o solo básico, no qual organicamente crescera todo o trabalho educativo-formativo da escola, como um todo único inseparável. Então, a própria questão sobre o que é o determinante no sistema de ensino: o trabalho ou o curso de disciplinas torna-se sem sentido, deixa de ser conteúdo (PISTRAK, 2009, p 206).

Mas como seria, nas escolas do campo, o vínculo do trabalho como princípio formativo no contexto da agricultura camponesa e a agroecologia? De acordo com Caldart (2016),

O vínculo das escolas com a agricultura camponesa e a agroecologia ajuda no alargamento da base formativa, exatamente por exigir que a educação se adentre ao âmago essencial da constituição do ser humano pelo trabalho, que é o desenvolvimento de suas forças produtivas pela relação metabólica entre o ser humano e a natureza, de que é parte. (CALDART, 2016, p 24)

Isso implica a inserção dos estudantes no trabalho da agricultura, a agroecologia ser considerada uma área de estudo, inserindo estudos sobre a natureza, sobre os aspectos técnicos e científicos que constituem a produção agrícola, sistemas alimentares nos quais a agricultura se insere (CALDART, 2016). Nesse aspecto, a escola do campo também deve contribuir para a formação de pessoas capazes de promover processos organizativos, seja no 
movimento sindical, nos movimentos sociais do campo, ou mesmo em cooperativas e associações. Essa capacidade organizativa é fundamental na construção social de mercados, na mobilização dos trabalhadores por políticas públicas específicas voltadas para o campo, ou até mesmo na organização produtiva, na organização para o desenvolvimento de práticas adequadas e adaptadas as realidades especificas da agroecologia. Portanto, a partir da agricultura camponesa e agroecologia, é possível estabelecer, pela mediação do trabalho, os princípios científicos que dão base a agroecologia e a capacidade de mobilização e organização política e produtiva de organizações e movimentos sociais do campo.

Uma das formas de organização das escolas do campo no Brasil se dá por meio da Pedagogia da Alternância ${ }^{11}$. A Pedagogia da Alternância é uma perspectiva ainda em construção no campo da educação, especificamente quando nos referimos a educação do campo. Além dessa construção conceitual e teórica, ainda lhe é atribuída diferentes significados, configurandoa como uma concepção ou "noção" polissêmica. A perspectiva histórica da pedagogia da alternância nos remetem a diferentes formas de organização do trabalho pedagógico inserindo diferentes lentes teóricas as intencionalidades atribuídas a essa organização. Em uma abordagem histórica, é possível identificar na França o início dessa "modalidade" pedagógica que traz em sua concepção, principalmente, a possibilidade de articular o trabalho e a escola, ou o trabalho e a formação escolar.

No Brasil, essa experiência se concretiza pelas Escolas Famílias Agrícolas, e as Casas Familiares Rurais. A base dessa pedagogia está diretamente vinculada a formação técnica e as práticas agrícolas desenvolvidas no meio sócio familiar dos educandos. A centralidade do trabalho, por meio das alternâncias educativas, portanto, se dá muito pelo vínculo entre os conhecimentos escolares, sistematizados e os conhecimentos práticos, principalmente vinculado ao mundo do trabalho no campo.

\footnotetext{
${ }^{11}$ Existem diferentes experiências engendradas no âmbito dos movimentos sociais do campo, especificamente o MST, de escolas itinerantes, de escolas fundadas na perspectiva da escola do trabalho e de organização dos conteúdos por meio de complexos de estudos. A própria organicidade do movimento se dá baseado nos preceitos da escola do trabalho.
}

TrabalhoNecessario - www.uff.br/trabalhonecessario; Ano 15, № 27/2017 
Ribeiro (2009), analisando a relação trabalho e educação no movimento camponês, nos traz a contribuição sobre como a abordagem do trabalho como princípio educativo está presente na pedagogia da alternância, que procura fazer a relação direta da realidade dos educandos com a estruturação da matriz formativa dos processos educativos estabelecidos nessa formação, ou seja, no currículo. Sendo assim "(...) a pedagogia da alternância tem o trabalho como princípio educativo de uma formação humana integral ao articular dialeticamente o trabalho produtivo, praticado na agricultura, pecuária e pesca, ao ensino formal, efetuado na escola básica, profissional ou superior" (RIBEIRO, 2009, p. 125).

A relação estabelecida nos diferentes espaços/tempos de formação, por meio da pedagogia da alternância deve levar em consideração que os indivíduos "(...) já possuem conhecimento elaborados, experiências práticas e vivências que devem ser consideradas como ponto de partida (RIBEIRO, 2009, p. 48). Rummert (2009), ao analisar os desafios teóricos e metodológicos da educação de jovens e adultos trabalhadores, sob a ótica do conceito de experiência, de Thompson, traz a reflexão sobre os riscos de, na tentativa de organização curricular que traga a experiência dos trabalhadores, se estabeleça processos educativos uniformes e padronizantes. Destaca a estruturação necessária de práticas educativas que promovam “(...) 0 alargamento os horizontes e a ampliação dos saberes da classe trabalhadora (....)" (RUMMERT, 2009, p 41) por meio de uma dialética necessária entre saberes e experiências.

A pedagogia da Alternância possui instrumentos que tem por objetivo vincular tempos/espaços de formação. De acordo com Ribeiro (2009) na alternância entre diferentes tempos/espaços "valorizam-se os saberes construídos nas práticas sociais, principalmente a experiência do trabalho (...)" (RIBEIRO, 2009, p. 125). Os instrumentos que tentam vincular a realidade dos educandos de forma a orientar as discussões previstas no currículo, temos a Colocação em Comum e o plano de Estudos. Esses dois instrumentos são articulados. A partir da colocação em comum, de acordo com Gimonet (2007), tem-se "(...) a passagens em transições de um lugar de vida a outro, de um tipo 
de experiência a outro, de um campo de conhecimento a outro (...)" (GIMONET, 2007, p. 43). O pressuposto fundamental desses instrumentos é trazer elementos e saberes do trabalho para centralidade dos processos de ensino aprendizagem. Sendo assim, a elaboração do plano de estudos e a colocação em comum dos resultados dos trabalhos elaborados pelos estudantes é um elemento importante de organização dos conteúdos e das abordagens teóricas que serão desenvolvidas.

Tem-se, portanto, um vínculo intimo entre Escola do Trabalho e Escola do Campo. Os instrumentos utilizados na Escola Comuna, sistematizada por Pistrak (2009), principalmente ao que se refere a atualidade e a autoorganização dos estudantes, também está presente na pedagogia da alternância. Uma aproximação em termos de concepção, tendo em vista que seria necessária uma análise empírica do uso desses instrumentos, entre os planos de estudos utilizados na pedagogia da alternância e os complexos de estudos utilizados na escola do trabalho é possível. O trabalho como elemento central do processo de ensino aprendizagem e como articulador das bases científicas dos processos produtivos é uma aproximação possível.

Nesse sentido, a agricultura camponesa e a agroecologia, articulados com o trabalho camponês dão as bases para estruturação de processos educativos nas escolas do campo, tendo como objetivo maior a superação das contradições que compõe o campo brasileiro. A produção do conhecimento agroecológico, portanto, pode ser desenvolvida por meio das escolas do campo, tendo o trabalho como princípio educativo e formativo dos trabalhadores do campo.

\section{4 - Conclusão}

O presente texto objetivou refletir sobre a produção do conhecimento agroecológico na busca de indicar os fundamentos da (s) pedagogia (s) agroecológica. $\mathrm{Na}$ relação entre trabalho, agricultura camponesa e agroecologia, é possível identificar por meio do processo histórico de

TrabalhoNecessario - www.uff.br/trabalhonecessario; Ano 15, № 27/2017 
desenvolvimento de processos sociais voltados para a promoção da agroecologia, estabelecidos por movimentos sociais do campo, que existe um vínculo estreito entre processos locais de organização dos camponeses, dos saberes produzidos por meio da experiência, com as técnicas e metodologias participativas de intervenção social, estabelecidas no âmbito do "movimento agroecológico".

Para além dos processos estabelecidos nos movimentos sociais, tem-se nas escolas do campo um processo de produção do conhecimento, ancorados nas experiências da escola do trabalho, em que o trabalho é o mediador do processo de produção do conhecimento. Nesse sentido, há uma aproximação entre escolas do campo e escola do trabalho, na forma de organização dos conteúdos e na abordagem teórica de produção do conhecimento, vinculado a realidade vivida dos camponeses.

Sendo assim, tanto no âmbito dos movimentos sociais, quanto no âmbito das escolas do campo, é possível identificar os fundamentos da escola do trabalho na construção da (s) pedagogia (as) agroecológica (s), em que a partir da agroecologia e da agricultura camponesa se constituiu as bases cientificas sistematizadas por meio dos saberes do trabalho e da experiência que estruturam a análise da realidade na produção do conhecimento agroecológico.

\section{5 - Referência Bibliográfica}

ALENTEJAO, P. Modernização da Agricultura. In: CALDART, R., PEREIRA, I.B., ALENTEJANO, P., FRIGOTTO, G. (Org.) Dicionário da Educação do Campo. Expressão Popular. Escola Politécnica de Saúde Joaquim Venâncio. Rio de Janeiro -São Paulo, 2012.

ALMEIDA, J. Da ideologia do Progresso à ideia do desenvolvimento (rural) sustentável. In: ALMEIDA, J., NAVARRO, Z. (Org.). Reconstruindo a agricultura: idéias e ideais na perspectiva de um desenvolvimento rural sustentável. Porto Alegre: Editora da Universidade, UFRGS, 1997.

CALDART, Roseli. Trabalho, agroecologia e educação politécnica nas escolas do campo In: PIRES, Joao Henrique, NOVAES, Henrique T., MAZIN, Ângelo e LOPES, Joyce (org.). Questão Agrária, Cooperação e Agroecologia, vol. III. São Paulo: Outras Expressões, 2016. 
COELHO, France Maria Gontijo. A arte das orientações técnicas no campo: concepções e métodos. 2 ed. Viçosa, MG: Suprema, 2014.

FAVARETO, A. Agricultores, Trabalhadores: os trinta anos do novo sindicalismo rural no Brasil. Revista Brasileira de Ciências Sociais, São Paulo, v. 21, n. 62, out. 2006, p.28-44.

FRIGOTTO, G. A dupla face do trabalho: criação e destruição da vida. In: FRIGOTTO, G.; CIAVATTA, M (orgs.) A experiência do trabalho e a educação básica. $2^{a}$ ed. Rio de Janeiro: DP\&A, 2005, pp -11-27

GIMONET, Jean-Claude. Práticar e compreender a pedagogia da alternância dos CEFFAS. Petrópolis, RJ: Vozes, Paris: 2007.

MARX, K. O Capital: Crítica da Economia Política: livro I. 31 ed. Rio de Janeiro: Civilização Brasileira, 2013. pp 211- 231

MOLINA, M. C.; SÁ, L. M. Licenciatura em Educação do Campo. In: CALDART, R. S.; PEREIRA, I. B.; ALENTEJANO, P.; FRIGOTTO, G. (Orgs). Dicionário de Educação do Campo. Rio de Janeiro, São Paulo: Escola Politécnica de Saúde Joaquim Venâncio, Expressão Popular, 2012. p.468-474.

RIBEIRO, Marlene. Trabalho-Educaçao no Movimento Operário e no Movimento Camponês: Unidade na Diversidade. In: CANÁRIO, Rui., RUMMERT, Sonia. (ORGs) Mundos do Trabalho e Aprendizagem. Educa, Lisboa, 2009.

PETERSEN, P. e ALMEIDA, S.G. de. Rincões transformadores: trajetória e desafios do movimento agroecológico brasileiro - uma perspectiva a partir da Rede PTA. ASPTA, Rio de Janeiro, (mimeo), 2006.

PISTRAK, M.M. A Escola Comuna. 2a Ed. Editora Expressão Popular. São Paulo - 2013

PLOEG, J. D. Camponeses e impérios alimentares: lutas por autonomia e sustentabilidade na era da globalização. Tradução Rita Pereira. Porto Alegre: Editora da UFRGS, 2008

RIBEIRO, Ricardo. O trabalho como princípio educativo: algumas reflexões. Saúde e Sociedade. V.18, supl.2.2009.

RUMMERT, Sonia Maria. Desafios teóricos e metodológicos da educação de jovens e adultos trabalhadores. In: CANÁRIO, Rui. RUMMERT, Sonia Maria. (orgs). Mundos do trabalho e aprendizagem. EDUCA, Lisboa, 2009. P 29-44.

SAVIANI, D. Trabalho e Educação: Fundamentos Ontológicos e Históricos.

Revista Brasileira de Educação. V12, n 34 jan/abr 2007.

SAVIANI, D. Pedagogia histórico crítica: primeiras aproximações. 11 ed. rev. Campinas, SP. Autores Associados, 2013

SILVA, Márcio Gomes da.; DIAS, Marcelo Miná.; SILVA, Sandro Pereira. Relações e Estratégias de (Des) envolvimento Rural: políticas públicas, 
agricultura familiar e dinâmicas locais no município de Espera Feliz (MG), In RESR, Piracicaba -SP, vol. 52, n.02, p 229-248, abr/jun 2014.

SILVA, Marcio Gomes da; SANTOS, M. L..A prática educativa dos movimentos sociais na construção da agroecologia. Educação em Perspectiva (Online), v. 07 , p. $263 \cdot 282,2016$

SILVEIRA, Zuleide Simas da. Concepções de educação tecnológica na reforma da educação superior: finalidades, continuidades e rupturas estudo comparado Brasil Portugal (1995-2010). Niterói, 2011. 445f. Tese (Doutorado em Educação). Faculdade de Educação, Universidade Federal Fluminense, Niterói, 2011, pp. 131-163

TOLEDO, Víctor. BARRERA-BASSOLS, Narciso. A memória biocultural: a importância ecológica das sabedorias tradicionais. 1르 Ed. Editora Expressão Popular, São Paulo, 2015.

TIRIBA, Lia. Educação Popular e Pedagogia da Produção Associada.

Cad.Cedes, Campinas, vol.27,n.71, p.85-98,jan/abri.2007.

TIRIBA, Lia., FISCHER, Maria Clara Bueno. De olho no conhecimento "encarnado" sobre trabalho associado e autogestão. In: CANARIO, Rui; RUMMERT (ORGS) Mundos do Trabalho e Aprendizagem. Lisboa, 2009.

TIRIBA, Lia.; SICHI, Bruna. Cios da Terra: Saberes da experiência e saberes do trabalho associado. Revista Trabalho Necessário, ano 10, n.15. Faculdade de Educação; NEDDATE, Universidade Federal Fluminense, Niterói, 2012.

WEZELL, A.; BELLON, S.; DORE, T.; FRANCIS, C.; VALLOD, D.; DAVID, C. (2009). Development Agroecology as a science, a movement and a practice. A review. Agron.Sustain. Dev. 13p.

Recebido em: 05 de julho de 2017 Aprovado em: 03 de outubro de 2017 Publicado em: 5 de dezembro de 2017 